\title{
Posterior transpedicular approach with circumferential debridement and anterior reconstruction as a salvage procedure for symptomatic failed vertebroplasty
}

Yen-Chun Chiu, Shih-Chieh Yang ${ }^{*}$, Hung-Shu Chen, Yu-Hsien Kao and Yuan-Kun Tu

\begin{abstract}
Background: Complications and failure of vertebroplasty, such as cement dislodgement, cement leakage, or spinal infection, usually result in spinal instability and neural element compression. Combined anterior and posterior approaches are the most common salvage procedure for symptomatic failed vertebroplasty. The purpose of this study is to evaluate the feasibility and efficacy of a single posterior approach technique for the treatment of patients with symptomatic failed vertebroplasty.

Methods: Ten patients with symptomatic failed vertebroplasty underwent circumferential debridement and anterior reconstruction surgery through a single-stage posterior transpedicular approach (PTA) from January 2009 to December 2011 at our institution. The differences of visual analog scale (VAS), neurologic status, and vertebral body reconstruction before and after surgery were recorded. The clinical outcomes of patients were categorized as excellent, good, fair, or poor based on modified Brodsky's criteria.

Results: The symptomatic failed vertebroplasty occurred between the T11 and L3 vertebrae with one- or two-level involvement. The average VAS score was 8.3 (range, 7 to 9 ) before surgery, significantly decreased to 3.2 (range, 2 to 4 ) after surgery $(p<0.01)$, and continued to decrease to 2.4 (range, 2 to 3$) 1$ year later $(p<0.01)$. The average correction of Cobb's angle after surgery was $17.3^{\circ}$ (range, $4^{\circ}$ to $\left.35^{\circ}\right)(p<0.01)$. The mean loss of Cobb's angle correction after 1 year of follow-up was $2.7^{\circ}$ (range, $0^{\circ}$ to $5^{\circ}$ ). The average allograft subsidence at 1 year after surgery was $1 \mathrm{~mm}$ (range, 0 to 2). The neurologic status of Frankel's scale significantly improved after surgery $(p=0.014)$ and at 1 year after surgery $(p=0.046)$. No one experienced severe complications such as deep wound infection or neurologic deterioration. All patients achieved good or excellent outcomes after surgery based on modified Brodsky's criteria $(p<0.01)$.
\end{abstract}

Conclusions: Single-stage PTA surgery with circumferential debridement and anterior reconstruction technique provides good clinical outcomes and low complication rate, which can be considered as an alternative method to combined anterior and posterior approaches for patients with symptomatic failed vertebroplasty.

Keywords: Cement dislodgement, Cement leakage, Failed vertebroplasty, Posterior transpedicular approach, Spinal infection

\footnotetext{
* Correspondence: isuspine@gmail.com

Department of Orthopedic Surgery and Anesthesiology, E-Da Hospital/-Shou

University, 1, E-Da Road, Kaohsiung City, Taiwan
} 


\section{Background}

Percutaneous vertebroplasty (PV) is a minimally invasive procedure which was first developed by Galibert and Deramond for the treatment of hemangioma in 1987 [1]. This technique involves a posterior transpedicular approach (PTA) using a spinal needle under fluoroscopic guidance and injection of polymethyl-methacrylate (PMMA) cement into a collapsed vertebral body. Thereafter, it has become a widespread procedure for management of osteoporotic vertebral compression fracture (VCF), multiple myeloma, lymphoma, and metastatic spinal tumor [2-5].

The use of PV for osteoporotic VCF can achieve significant pain relief and satisfactory clinical outcomes. However, the long-term results remain unpredictable [6-8]. Symptomatic complications and failure of vertebroplasty are uncommon and most of them can be resolved by conservative methods. Surgical intervention is indicated for some circumstances, such as spinal instability and neural element compression due to cement dislodgement, cement leakage, and spinal infection [9]. The standard salvage procedure required a combined surgical technique, which involves anterior transthoracic or retroperitoneal approach for direct debridement and decompression, accompanied by bone grafting or body spacer reconstruction, and posterior approach for supplemental posterior instrumentation and fusion. However, most patients with symptomatic failed vertebroplasty are elderly and have rather poor health status. These patients may not be amenable to an anterior approach due to poor pulmonary function, concurrent medical illness, previous surgery, or previous radiation therapy. Additionally, the disadvantages of combined approaches, including the requirement of prolonged anesthetic and surgical sessions, separated surgical wound, and the need to perform diaphragm takedown and rib cutting, tend to hurt this fragile population $[10,11]$.

In an attempt to decrease the morbidity associated with the combined surgical procedures, a single-stage technique using PTA, with circumferential decompression and reconstruction, has been proposed. Many surgeons have used this technique to treat patients with spinal disorders caused by metastatic tumor, infection, or burst fracture [12-15]. To our knowledge, there is no previous study using this technique as a salvage procedure for complications and failure of vertebroplasty. The purpose of this study is to evaluate the feasibility and efficacy of this single-stage PTA surgery for the treatment of patients with symptomatic failed vertebroplasty. We also examined and compared the clinical outcomes and radiographic findings of these patients before and after surgery.

\section{Materials and methods Patients}

The study population comprised 787 consecutive patients who underwent PV for treatment of osteoporotic VCFs from January 2009 to December 2011 at our institution. One-level vertebroplasty was performed in 582 patients, 2 levels in 140, 3 levels in 39, 4 levels in 22, 5 levels in 3, and 6 levels in 1 patient. After a comprehensive review of the medical records, 10 patients who had failed vertebroplasty and underwent a revised single-stage PTA surgery were enrolled in the study. There were 7 women and 3 men with an average age of 77.9 years (range, 69 to 90 years). The patients' medical records, including outpatient and emergency room notes, admission notes, inpatient progress and nursing notes, discharge summaries, procedure notes, surgical reports, radiology reports, pathology reports, and microbiology laboratory results, were reviewed.

These 10 patients with failed vertebroplasty had symptoms of progressive back pain with or without sciatica, which could not be controlled by conservative treatment. Conservative treatment included pain-killers for back pain, braces for spinal instability, and intravenous antibiotics for pyogenic spondylitis. The single-stage PTA surgery was performed for these patients after failure of the conservative treatment. Radiographic assessment was carried out before and after surgery, at the 3-, 6-, and 12-month visit after discharge and every year thereafter. The patients were followed up at our outpatient department 1 week, 1 month, 3 months, and then every 3 months thereafter. All 10 enrolled patients were followed up for at least 12 months after undergoing the revised single-stage PTA surgery.

\section{Surgical technique}

\section{Exposure and posterior stabilization}

After induction of general anesthesia, a midline incision from 2 levels above the involved vertebrae to 2 levels below was made to expose the posterior complex. The exact level was identified by intraoperative $\mathrm{C}$-arm fluoroscopy and the exposed level was adjusted accordingly. Transpedicular screws were introduced 2 levels above and 2 levels below the involved vertebrae initially. The devices used for instrumentation included USS and ClickX (Synthes, Solothurn, Switzerland). Then, the laminectomy procedure was started and a rod was used temporarily if spinal instability was found after removal of the posterior complex. Since a bulky rod could influence allograft insertion access and transpedicular debridement, the temporary rod was placed to conduct the screws on the contralateral side of the planned allograft insertion. One rod could maintain adequate stability after extensive posterior complex decompression and prevent injury to the neural elements by any undesired manipulated vibration. The planned insertion site was decided based on the preoperative image survey and neurologic findings. Sometimes, bilateral transpedicular debridement was indicated for extensive debridement. In this situation, we placed another rod on the other side which has been finished of debridement and then released the 
previously fixed rod to continue contralateral debridement; therefore, decompression of both sides could be achieved.

\section{Decompression}

Facetectomy was performed above and below the involved vertebrae to expose the involved pedicles and neurologic elements. A plane between the posterior longitudinal ligament and the dura was created by blunt dissection. The circumferential debridement procedure was accomplished using PTA through the route of the interval between the nerve roots. A unilateral approach was used if only one side of the neurologic elements was compressed by the protrusion of the fractured vertebral body or leaked bone cement, and a bilateral approach was used if both sides were involved. Ligation and sacrifice of the nerve root were not necessary because the working space was adequate. Although total corpectomy was feasible using the PTA, subtotal vertebrectomy was usually performed to remove the bone cement fragment as completely as possible and create an adequate space for fibular allograft implantation. The disks above and below the cemented vertebrae were removed to prepare the adjacent endplates. The anterior structures, either the anterior cortex or anterior longitudinal ligament, which provided protection of the anterior vessels, diaphragm, visceral organs, or some vital structures, were preserved in most cases.

\section{Anterior column reconstruction}

After the neural elements were completely decompressed, we gently distracted the 2 screws above and below the involved vertebrae by using a distractor on the rod. During distraction, we needed to observe the nerve roots and spinal cord tension to prevent traction injury of the neural elements. The length of the bony defect was then measured. An adequate length of freeze-dried fibular allograft was prepared and procured. Multiple drilling using Kirschner wires was performed on both ends of the allograft to facilitate bony incorporation between the fibular allograft and the vertebral body. The fibular allograft was introduced through the route between the nerve roots. After the allograft was well deposited, we released the distraction on the rod and then constructed both rods and a link for immediate stability. Sometimes, we even compressed the adjacent instrumentation to obtain good contact between the endplates and allograft and achieve better spinal alignment.

\section{Postoperative care}

After surgery, the neurologic status and hemodynamic status were checked regularly. We also administered antiosteoporosis drugs to every patient to decrease the possibility of screw loosening, fixation failure, and further compression fracture at other levels. Patients were mobilized by a chair or wheelchair on the first postoperative day; ambulation training was started if the pain and neurologic status could be tolerated. Taylor's brace or body jacket was arranged for protection of the spine. Eight of the patients received prophylactic antibiotics for 2 days. Two patients who underwent surgery due to spinal infection were prescribed for 6 weeks intravenous

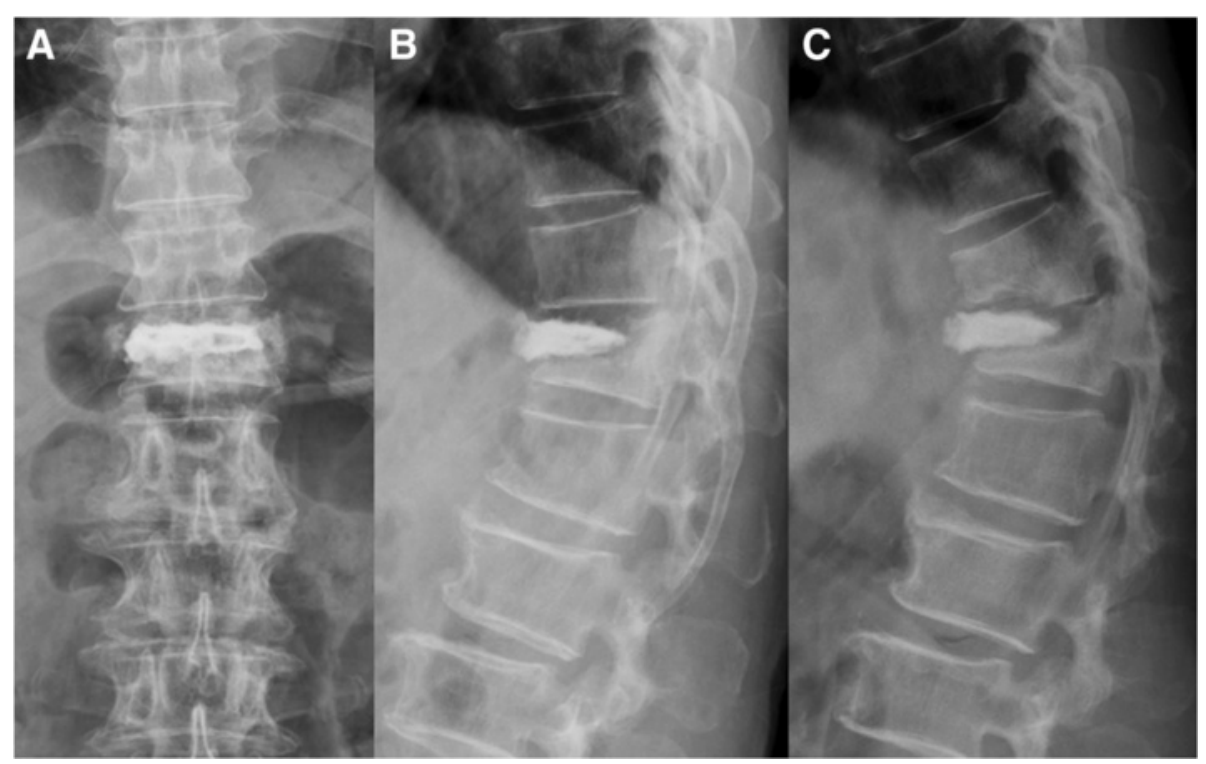

Figure 1 A 78-year-old man underwent PV for T12 osteoporotic VCF. The patient experienced intractable back pain and bilateral lower limb weakness after falling down and injuring himself. Anteroposterior radiograph (A) revealed a radiolucent line surrounding the bone cement. Lateral radiograph (B) revealed T12 bone cement anterior dislodgement. After 2 months of conservative treatment, the symptoms of back pain and leg weakness had worsened. The follow-up lateral radiograph (C) showed further cement dislodgement and T11 adjacent fracture with kyphotic deformity. 


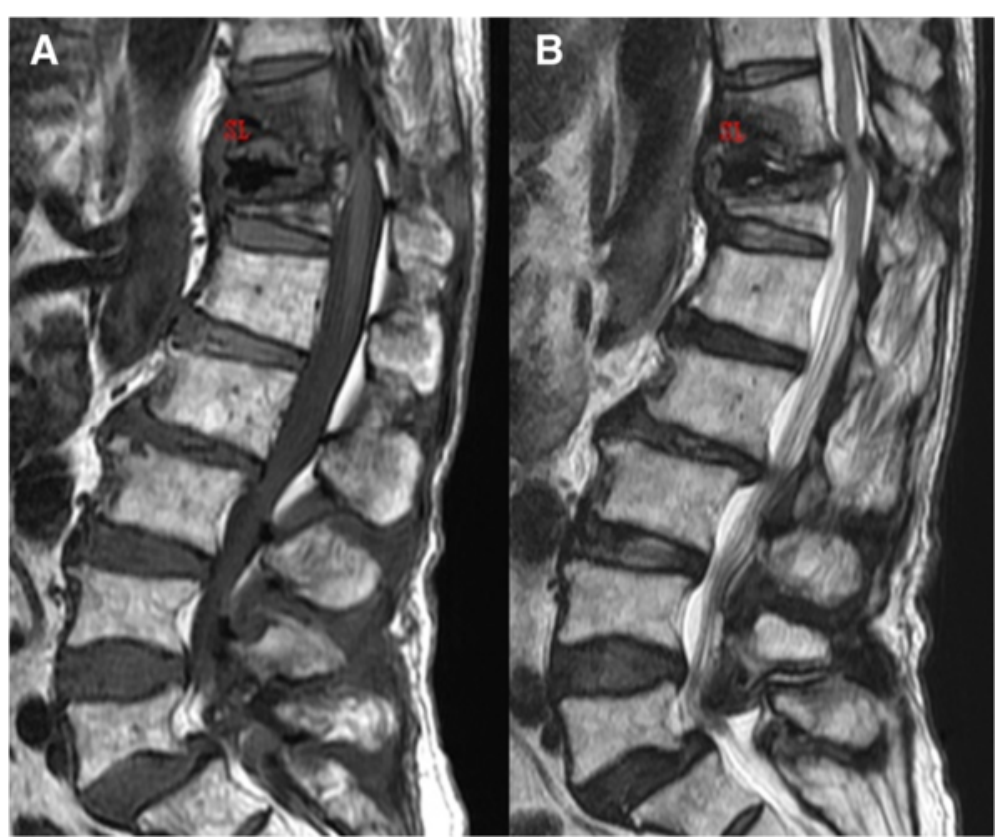

Figure 2 Sagittal MRI images. Sagittal T1-weighted MRI (A) showed T11 and T12 fracture with bone marrow edema. Sagittal T2-weighted MRI (B) revealed fluid accumulation surrounding T12 bone cement. Both sagittal T1- and T2-weighted MRI demonstrated T11 and T12 severe stenosis due to spinal instability.

antibiotics based on culture data. The culture data of both patients showed oxacillin-sensitive Staphylococcus aureus. The other 8 patients were discharged within 14 days after surgery and were followed up for at least 1 year at the outpatient department.

\section{Outcome assessment}

Clinical outcomes were assessed by asking the patients to evaluate their pain on a visual analog scale (VAS, using a scale of 0-10; 0 meaning no pain and 10 the most pain possible) and on the basis of pain, activity, and analgesics

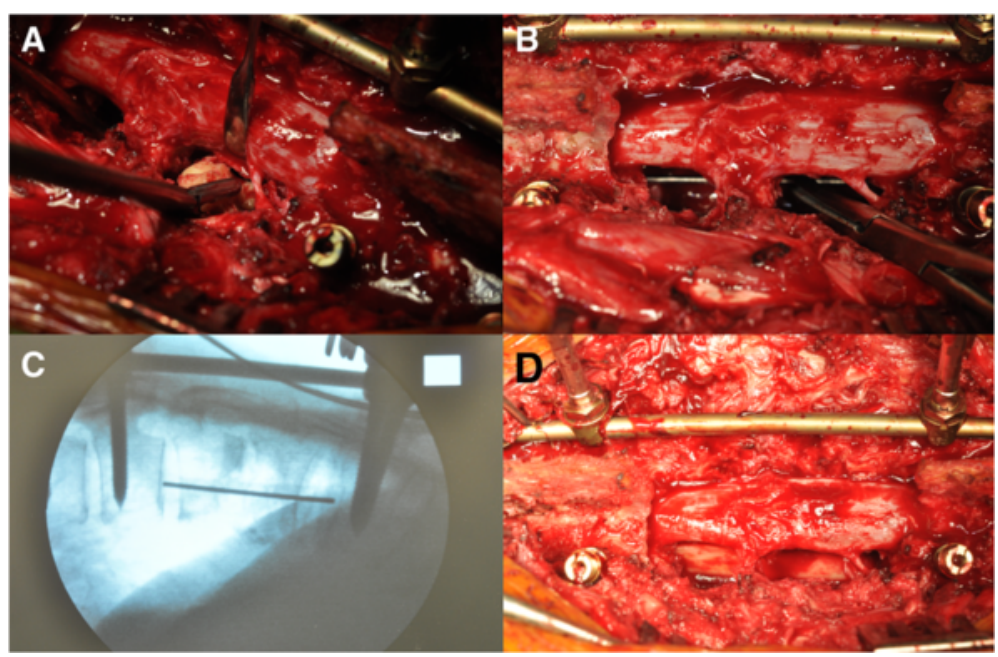

Figure 3 After adequate debridement through single-stage PTA surgery, the dislodged cement was identified and removed. A rod was temporarily placed on the contralateral side of the planned allograft insertion to prevent undesired vibration during operation (A). A Kirschner wire was used to measure an adequate length for the allograft (B). An intraoperative fluoroscope was used to make sure that the length was suitable. The Kirschner wire should touch the lower endplate of the upper vertebral body and upper endplate of the lower vertebral body (C). After gently retracting the rod, a well-prepared fibular allograft was inserted carefully through the route between the nerve roots. The rods were used to provide stability after adequate compression (D). 


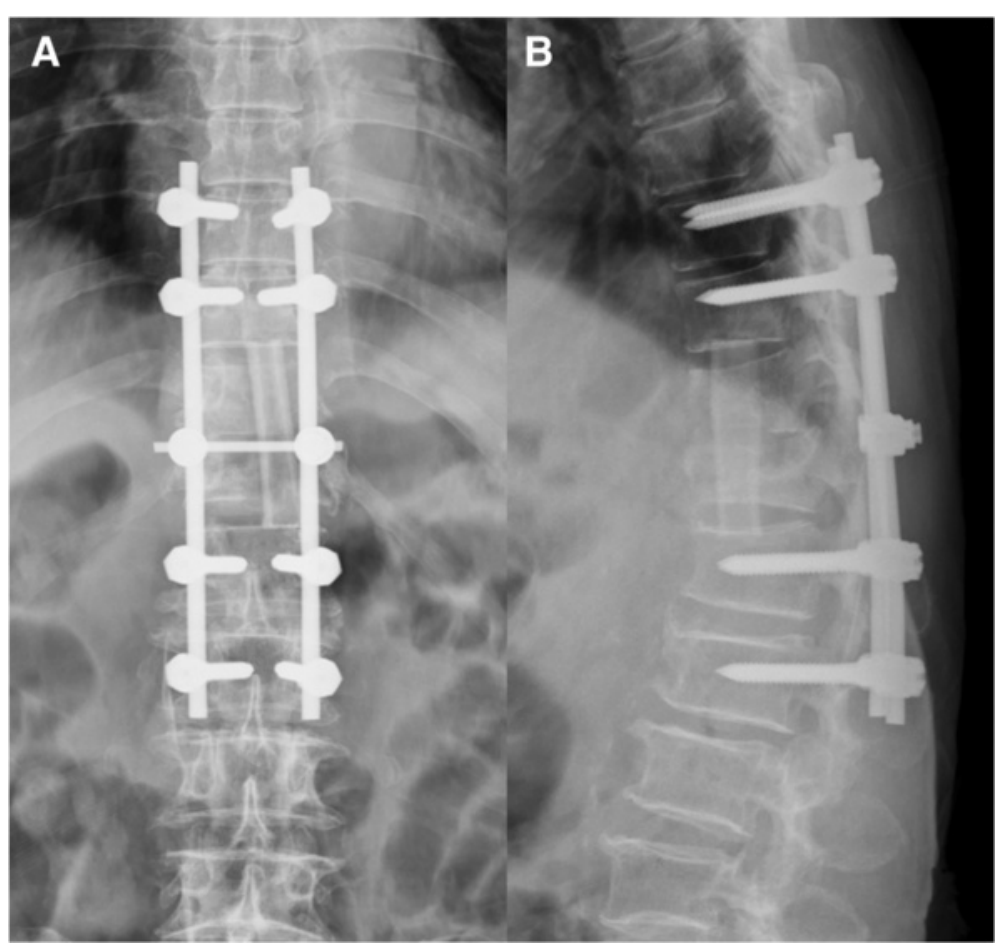

Figure 4 Postoperative radiographs. The postoperative anteroposterior (A) and lateral (B) radiographs revealed that the dislodged bone cement had been removed. Good correction of spinal alignment was achieved by fibular allograft implantation and posterior pedicle screw fixation.

requirement during admission, before discharge, and at 1 year follow-up to determine the modified Brodsky's criteria, which were categorized as poor, fair, good, and excellent [16]. The severity of the neurological status was evaluated using the Frankel scale before surgery, at discharge, and 1 year later. The correction of the sagittal Cobb's angle before surgery was compared with that at discharge and after surgery 1 year later using radiographic image examination. The Cobb's angle, defined as the angle between the superior endplate of the

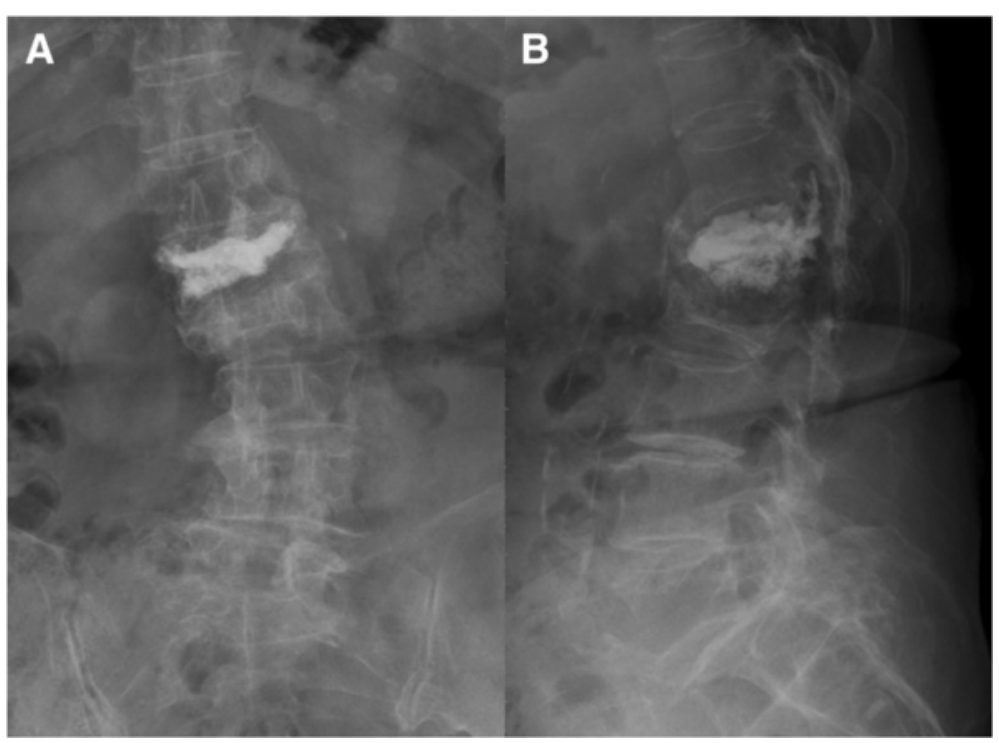

Figure 5 A 76-year-old woman who underwent L1 PV sustained progressive intractable back pain with bilateral lower limb numbness and weakness. The anteroposterior (A) and lateral (B) radiographs revealed cement leakage into the spinal canal and L2 adjacent fracture. 


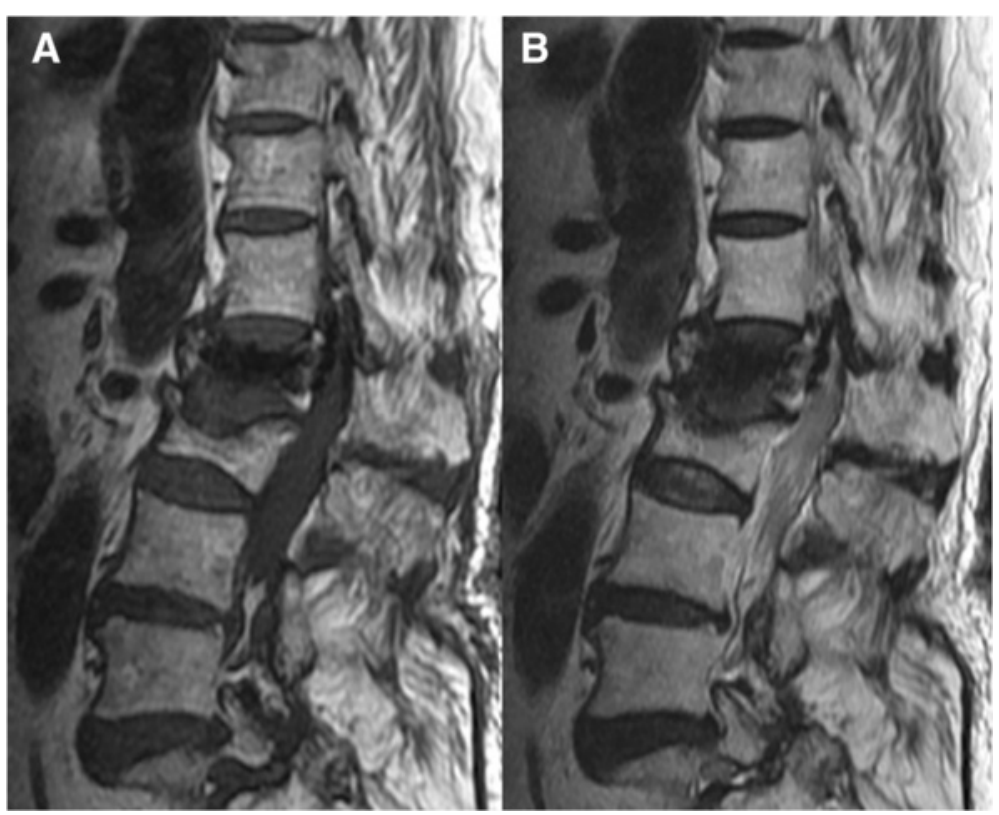

Figure 6 Sagittal MRI images. Sagittal T1-weighted MRI (A) and sagittal T2-weighted MRI (B) revealed bone cement leakage into the spinal canal with neural element compression.

cephalad-instrumented vertebra and the inferior endplate of the caudal-instrumented vertebra, was measured on plain lateral radiograph. The VAS, modified Brodsky's criteria, Frankel scale, and sagittal Cobb's angle before surgery were compared with those after surgery and 1 year later using the Wilcoxon signed-rank test. Nonparametric statistics were used because some variables did not have normally distributed data. SPSS 13.0 software (SPSS Inc., Chicago, USA) was used for data analysis. A value of $P<0.05$ was considered statistically significant.

\section{Results}

The average interval between initial vertebroplasties and revised single-stage PTA surgeries was 11.6 months (range, 1 to 25 months). Five patients had symptomatic failed vertebroplasty in 2 levels and 5 in 1 level, and all occurred between the T11 and L3 vertebrae. Six patients underwent instrumentation 2 levels above and 2 levels below the involved vertebrae, and 4 patients underwent instrumentation of extended levels due to the osteoporotic vertebrae. The indications for the revised single-stage PTA

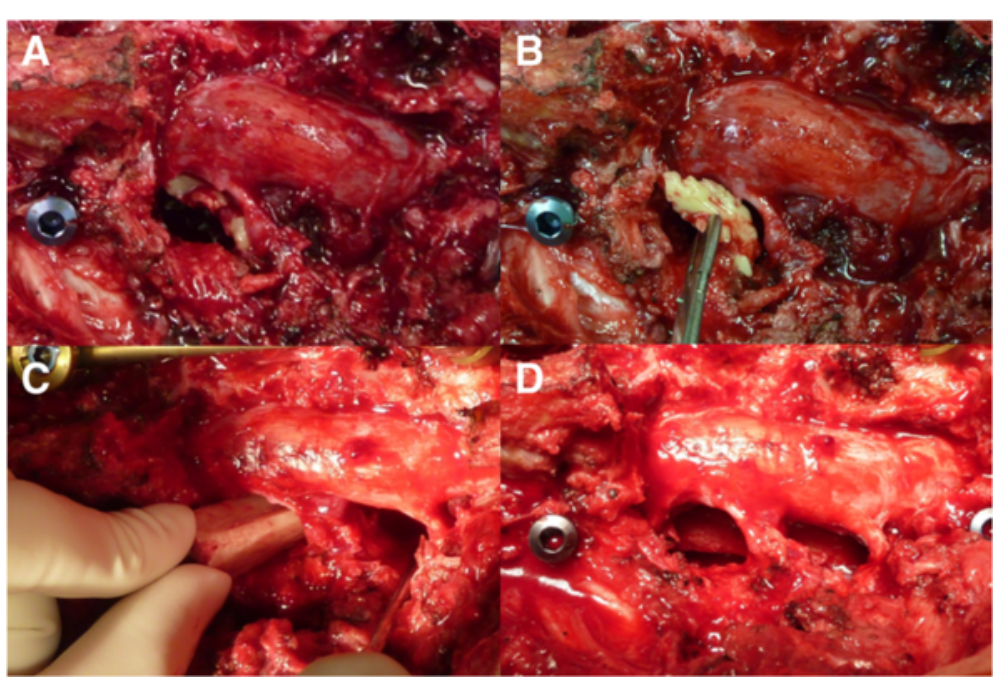

Figure 7 Cement leakage with neural element compression. The leaked cement fragment was identified after circumferential decompression through single-stage PTA surgery (A). The cement fragment was removed with a clamp (B). The fibular allograft was inserted through the route between the nerve roots after adequate debridement had been performed (C). The fibular allograft was finally well positioned (D). 


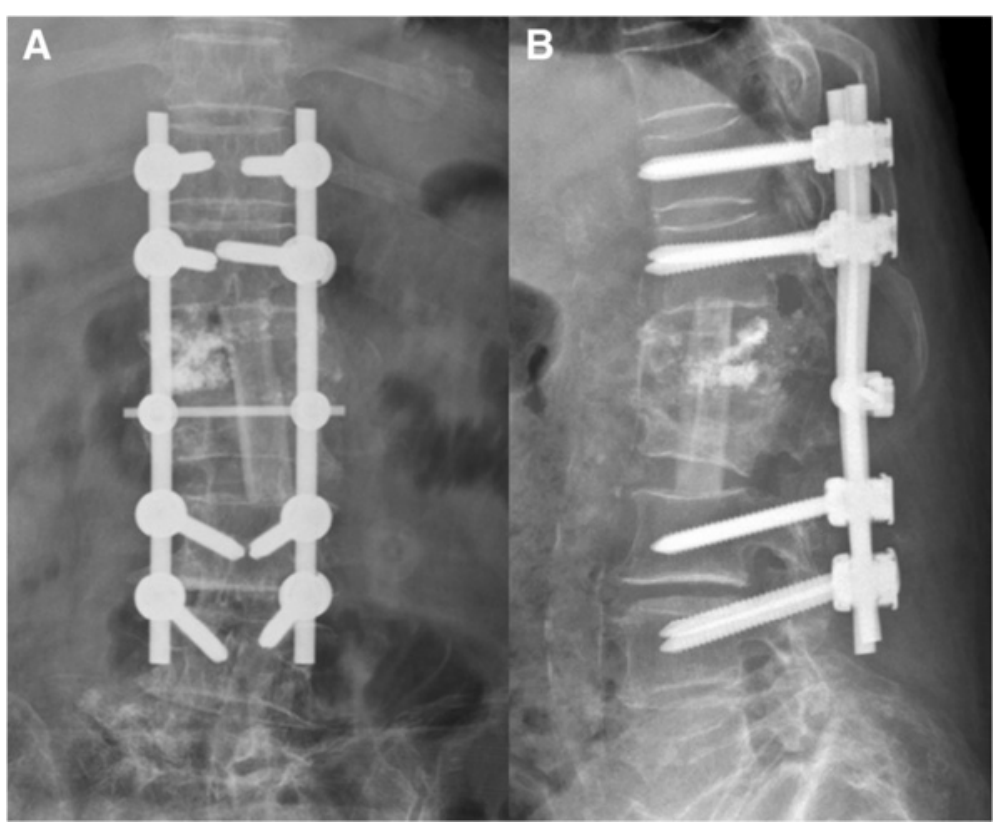

Figure 8 The postoperative anteroposterior (A) and lateral (B) radiographs revealed the leaked cement fragment within the spinal canal had been removed. There still was some residual cement with no influence on the neural elements. An acceptable spinal alignment was restored with an adequate length of fibular allograft implantation and posterior pedicle screw fixation.

surgery for these patients included cement dislodgement in 6 patients (Figures 1, 2, 3, and 4), cement leakage with neural element compression in 2 (Figures 5, 6, 7, and 8), and spinal infection in 2 . The average allograft length for reconstruction was $53.8 \mathrm{~mm}(67.4 \mathrm{~mm}$ in 2 failed levels and $40.2 \mathrm{~mm}$ in 1 failed level) (Table 1 ).

The most prominent clinical sign of the failed vertebroplasty was severe back pain, which significantly decreased from the average VAS of 8.3 (range, 7 to 9 ) before surgery to 3.2 (range, 2 to 4 ) before discharge $(p<0.01)$ and continually decreased to 2.4 (range, 2 to 3$) 1$ year later $(p<0.01)$
(Figure 9A). Modified Brodsky's criteria of all patients significantly increased from either poor or fair before surgery to good or excellent at discharge $(p<0.01)$ and 1 year later $(p<0.01)$ (Figure 9C). Neurologic status significantly improved, from the median of Frankel D before surgery to Frankel E before discharge $(p=0.014)$ and at the 1-year follow-up $(p=0.015)$ (Figure 9B). Only 5 patients still had abnormal neurologic function with Frankel D before discharge, and 4 of them improved to normal function 1 year later. No patients experienced neurologic deterioration after surgery (Table 2).

Table 1 Patient demographic data

\begin{tabular}{|c|c|c|c|c|c|c|c|}
\hline Case & Age (years) & Gender & Failed levels & $\begin{array}{l}\text { Time between PV and } \\
\text { surgery (months) }\end{array}$ & Instrumentation level & Failed mechanism & $\begin{array}{l}\text { Allograft } \\
\text { length }(\mathrm{mm})\end{array}$ \\
\hline 1 & 76 & $\mathrm{~F}$ & $\mathrm{~L} 1$ and $\mathrm{L} 2$ & 1 & T11T12 to L3L4 & Cement leakage & 65 \\
\hline 2 & 76 & $\mathrm{~F}$ & $\mathrm{~T} 12$ & 12 & T10T11 to L1L2 & Cement dislodgement & 39 \\
\hline 3 & 79 & $\mathrm{~F}$ & L1 & 5 & T10T11 to L3L4 & Infection & 38 \\
\hline 4 & 89 & M & $\mathrm{T} 12$ and L1 & 22 & T10T11 to L3L4 & Cement dislodgement & 69 \\
\hline 5 & 72 & $\mathrm{~F}$ & T11 and T12 & 1 & T7T9 to L2L3 & Cement leakage & 68 \\
\hline 6 & 71 & $\mathrm{~F}$ & $\mathrm{~L} 2$ and $\mathrm{L} 3$ & 9 & T12L1 to L4L5 & Cement dislodgement & 72 \\
\hline 7 & 90 & M & L3 & 20 & L1L2 to L4L5 & Cement dislodgement & 52 \\
\hline 8 & 69 & $\mathrm{~F}$ & $\mathrm{~T} 12$ & 25 & T9T11 to L3L4 & Cement dislodgement & 37 \\
\hline 9 & 78 & M & $\mathrm{T} 11$ and $\mathrm{T} 12$ & 18 & T9T10 to L1L2 & Cement dislodgement & 63 \\
\hline 10 & 79 & $\mathrm{~F}$ & L1 & 3 & T11T12 to L2L3 & Infection & 35 \\
\hline
\end{tabular}

$F$ female, $M$ male, $L$ lumbar spine, $T$ thoracic spine, $P V$ percutaneous vertebroplasty. 
The sagittal Cobb's angle was significantly corrected, from a mean angle of $-23.3^{\circ}$ (range, $-51^{\circ}$ to $-6^{\circ}$ ) before surgery to $-6.0^{\circ}$ (range, $-23^{\circ}$ to $\left.16^{\circ}\right)$ after surgery $(p<0.01)$ and $-8.7^{\circ}$ (range, $-25^{\circ}$ to $\left.13^{\circ}\right) 1$ year later $(p<0.01)$ (Figure 9D). Kyphotic deformity improved in all patients, with an average angle correction of $17.3^{\circ}$ (range, $4^{\circ}$ to $35^{\circ}$ ) immediately after surgery. One year later, the mean loss of Cobb's angle correction was $2.7^{\circ}$ (range, $0^{\circ}$ to $5^{\circ}$ ), and no bone graft dislodgement or screw loosening was found (Table 3). Surgery-related complications such as cerebrospinal fluid leakage, wound infection, pseudoarthrosis, nonunion, and loss of fixation were not encountered in our patient series during at least 1 year of follow-up.

\section{Discussion}

Treatment of complications and failure of vertebroplasty is a challenge for spinal surgeons because the proper salvage method for this complicated condition is still controversial $[9,17]$. A combined anterior and posterior surgery has been reported to be the most secure method. However, anterior approach to the spine, especially the upper thoracic and lower lumbar spine, is technically difficult and highly dependent on surgical experience. PTA with circumferential decompression and anterior reconstruction was developed to manage complicated spinal disorders, such as spinal tumor, infection, and burst fracture. Good clinical outcomes and low complication rate have been mentioned in the literature [12-15]. To our
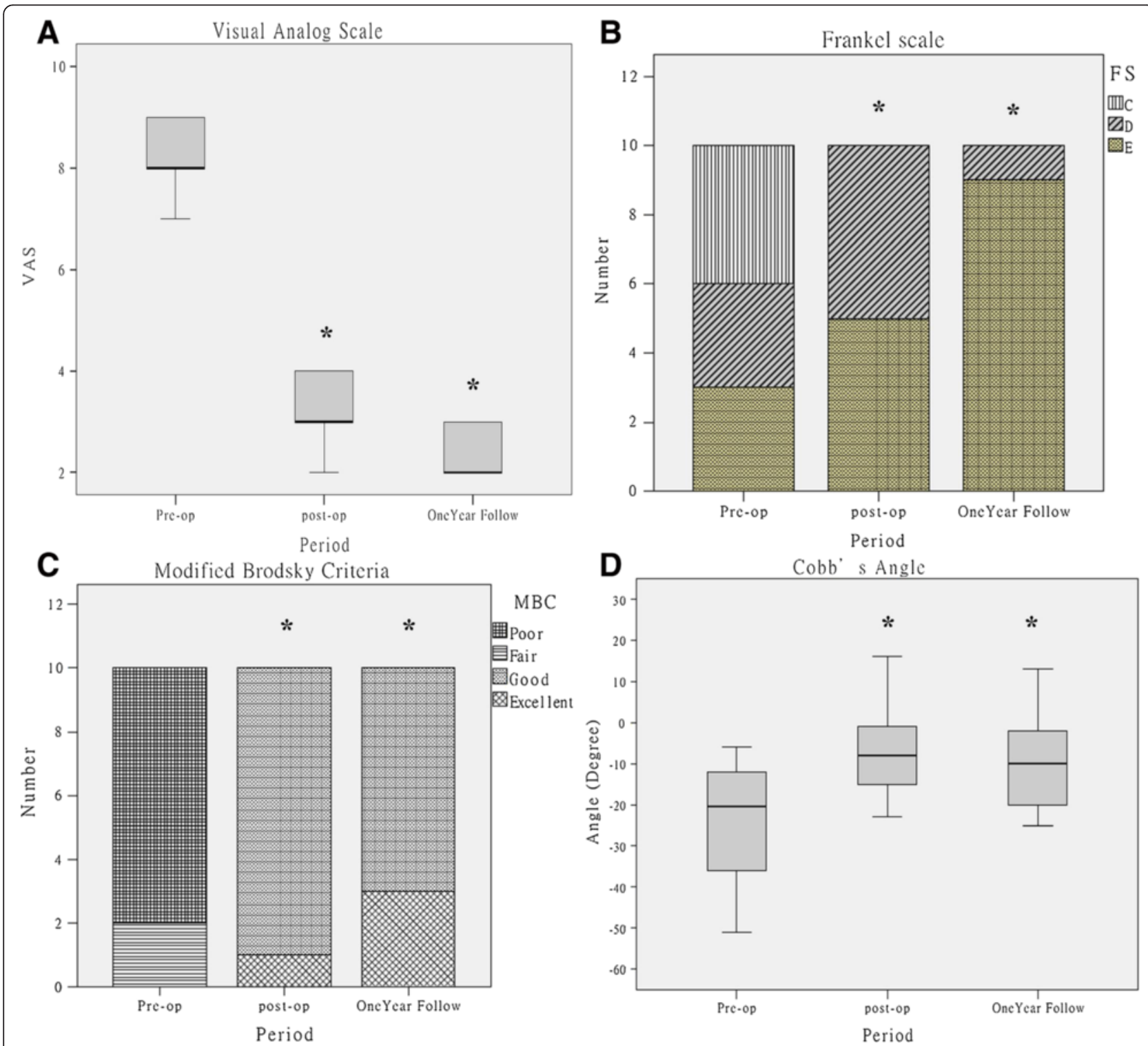

Figure 9 Comparison of clinical outcomes and radiographic findings before surgery, after surgery, and at the 1-year follow-up visit. Visual analog scale (A), Frankel's scale (B), modified Brodsky's criteria (C), and Cobb's angle (D). 
Table 2 The improvement of visual analog scale, Frankel's scale, and modified Brodsky's criteria before surgery, after surgery, and 1 year later

\begin{tabular}{|c|c|c|c|c|c|c|c|c|c|}
\hline Case number & Preop VAS & Postop VAS & $1 \mathrm{yr}$ VAS & Preop MBC & Postop MBC & $1 \mathrm{yr} \mathrm{MBC}$ & Preop FS & Postop FS & $1 \mathrm{yr} \mathrm{FS}$ \\
\hline 1 & 9 & 3 & 2 & $P$ & $G$ & G & $C$ & $\mathrm{D}$ & $E$ \\
\hline 2 & 7 & 3 & 3 & $\mathrm{~F}$ & E & $\mathrm{E}$ & $E$ & $\mathrm{E}$ & E \\
\hline 3 & 8 & 2 & 2 & $P$ & G & E & C & $\mathrm{D}$ & $E$ \\
\hline 4 & 9 & 4 & 3 & $\mathrm{P}$ & G & G & D & D & $\mathrm{E}$ \\
\hline 5 & 8 & 4 & 3 & $P$ & G & G & C & D & $\mathrm{D}$ \\
\hline 6 & 8 & 3 & 2 & $\mathrm{P}$ & G & G & D & $\mathrm{E}$ & $\mathrm{E}$ \\
\hline 7 & 9 & 3 & 2 & $P$ & G & $\mathrm{E}$ & $\mathrm{D}$ & $\mathrm{E}$ & $E$ \\
\hline 8 & 8 & 4 & 3 & $P$ & G & G & $\mathrm{E}$ & $\mathrm{E}$ & $\mathrm{E}$ \\
\hline 9 & 9 & 3 & 2 & P & G & G & C & $\mathrm{D}$ & $E$ \\
\hline 10 & 8 & 3 & 2 & $\mathrm{~F}$ & G & G & $\mathrm{E}$ & $\mathrm{E}$ & $E$ \\
\hline
\end{tabular}

Preop preoperative; Postop postoperative; 1 yr 1 year later; $V A S$ visual analog scale: 0 means no pain and 10 means the most pain possible; $M B C$ modified Brodsky's criteria: $P$ poor, $F$ fair, $G$ good, $E$ excellent; $F S$ Frankel's scale: $A$ complete paralysis, $B$ sensory function only below the injury level, $C$ incomplete motor function below injury level, $D$ fair to good motor function below injury level, $E$ normal function.

knowledge, the current study is the first report using this unique technique as a salvage procedure to treat patients with symptomatic failed vertebroplasty.

Six patients in this study underwent single-stage PTA surgery due to cement dislodgement resulting in spinal instability and associated stenosis. A proposed mechanism of this complication is a re-fracture of the cemented vertebrae at the stress junction of cement and bone or the posterior cortex defect, which allows relative motion of the cement block and results in final displacement with a further bending load [18]. The potential risk for cement dislodgment is an intravertebral vacuum cleft caused by avascular necrosis preoperatively [19]. Injection of PMMA into a cystic cavity would be expected to have far less interdigitation with the surrounding bone than injection into partially intact trabecular bone. The fluid in an intraosseous vacuum may isolate the cement filling in the fractures around it [20]. Therefore, PMMA cement may be only a space-occupying material without mechanical interlock and biocompatibility. As a result, further neural element irritation may occur due to direct compression by the posterior displaced bone cement and/or reactive stenosis by the hypertrophic facet joints and ligamentum flavum.

The complications related to cement leakage during vertebroplasties have been extensively discussed in the literature. Most of these complications are transient and minor in severity $[21,22]$. Cement leakage into the spinal canal frequently occurs with the presence of posterior vertebral cortex destruction. Cement leakage may be well tolerated if there is sufficient residual space for the spinal cord, but it could be a disaster if the spilled cement compresses the spinal cord and/or nerve roots, resulting in neurologic deficit $[23,24]$. Urgent decompression is indicated for these patients and the outcomes usually vary. In a retrospective study, Patel et al. reviewed the clinical course of 14 patients with documented loss of neurologic function following percutaneous vertebral

Table 3 The changes of radiographic findings before and after surgery

\begin{tabular}{|c|c|c|c|c|c|}
\hline Case number & $\begin{array}{l}\text { Preop Cobb's } \\
\text { angle }\left({ }^{\circ}\right)^{\mathrm{a}}\end{array}$ & $\begin{array}{l}\text { Postop Cobb's } \\
\text { angle }\left({ }^{\circ}\right)^{\mathrm{a}}\end{array}$ & $\begin{array}{l}\text { Correction of } \\
\text { Cobb's angle }\left({ }^{\circ}\right)\end{array}$ & $\begin{array}{l}\text { Loss of correction } \\
\text { at } 1 \text { year }\left({ }^{\circ}\right)\end{array}$ & Allograft subsidence $(\mathrm{mm})$ \\
\hline 1 & -10 & -1 & 9 & 1 & 1 \\
\hline 2 & -21 & -7 & 14 & 0 & 0 \\
\hline 3 & -13 & -9 & 4 & 2 & 1 \\
\hline 4 & -39 & -23 & 16 & 2 & 1 \\
\hline 5 & -12 & -5 & 7 & 4 & 1 \\
\hline 6 & -20 & 15 & 35 & 5 & 2 \\
\hline 7 & -6 & 16 & 22 & 3 & 1 \\
\hline 8 & -36 & -15 & 21 & 5 & 2 \\
\hline 9 & -51 & -22 & 29 & 2 & 1 \\
\hline 10 & -25 & -9 & 16 & 3 & 1 \\
\hline
\end{tabular}


cement augmentation. Six patients developed neurologic deficits acutely (less than $24 \mathrm{~h}$ ), and the remaining 8 patients developed neurologic symptoms at an average of 37.1 days (range, 3-112 days). Twelve of 14 patients (85.7\%) required revision open surgery for treatment of their neurologic injury [25]. Two patients with neurologic deficits due to cement leakage into the spinal canal were included in our study. Progressive onset of neurologic disorders may result from leaked bone cement and associated spinal instability. Single-stage PTA surgery allowed these patients early mobilization and rehabilitation regardless of their neurologic status, therefore yielding good functional recovery and decreasing overall morbidity and mortality.

Spinal infection is uncommon after vertebroplasties [26]. Most of these patients can be treated successfully with conservative methods. There are four main indications for surgery: failure of a CT-guided biopsy or blood culture to yield an organism, thus necessitating open or percutaneous retrieval of more tissue; failure of medical therapy; development of neurological disorder; and structural decompensation. The algorithm for surgical treatment requires considering four goals of management: thorough radical debridement, relieving pressure on neural elements, restoring normal alignment, and providing rigid fixation. The anterior approach is favored by many surgeons because of the direct assessment of pathogen debridement and accompanied reconstruction of the anterior column. Although it could be an effective method, significant morbidity, including vascular, visceral, or pulmonary complications, is still a major concern for this procedure [27]. In a clinical study, 85 patients were treated using an anterolateral transthoracic approach for various lesions of the thoracic and thoracolumbar spine. The reported rate of severe approach-related complications occurred in 4 patients (4.7\%) [28]. The anterior approach is also poorly tolerated by patients with poor pulmonary function because lung deflation is needed during this approach. Visocchi et al. have proposed that if preoperative evaluation shows a partial pressure of oxygen $\left(P_{\mathrm{O} 2}\right)$ of less than $60 \mathrm{mmHg}$, partial pressure of carbon dioxide $\left(\mathrm{PCO}_{2}\right)$ of more than $45 \mathrm{mmHg}$, oxygen $\left(\mathrm{O}_{2}\right)$ saturation below $90 \%$, forced vital capacity (FVC) less than $1.5 \mathrm{~L}$, forced expiratory volume in $1 \mathrm{~s}\left(\mathrm{FEV}_{1}\right)$ less than $1 \mathrm{~L}$, and $\mathrm{FEV}_{1} / \mathrm{FVC}$ less than $35 \%$, the transthoracic approach is contraindicated [29]. Most patients undergoing vertebroplasty are elderly and have other comorbidities. With these coexisting underlying diseases, the anterior approach becomes risky for these patients. Additionally, most vertebroplasties for osteoporotic VCFs are performed at the thoracolumbar junction. A diaphragm takedown procedure is necessary if the anterior approach is used for lesions at the thoracolumbar junction, and this may lead to pulmonary function impairment after surgery.
Nerve root ligation and sacrifice to create a wider working space are common during the procedure of posterior approach at thoracic levels. However, rhizotomy may result in dysesthetic pain syndrome. Different from costotransversectomy or lateral extracavitary approach, PTA provides a safe corridor to access the anterior thoracolumbar column. Circumferential debridement, including bone cement removal and partial corpectomy, can be achieved piece by piece using clamps or rongeurs, through the route between the nerve roots. Therefore, the nerve roots can be intact preserved. Additionally, the space is also adequate for fibular allograft implantation. A corpectomy defect was traditionally reconstructed with structural autologous bone grafts from the iliac crest or fibula, which may cause an increase in permanent donor site morbidity up to $25 \%$ [30,31]. The concern about donor site-related complications has led the authors to use allogenous bone grafts for the reconstruction. An ideal graft construct should have the ability of bony incorporation without collapse and with the fewest undesired complications. A cortical graft such as a cadaveric humerus or fibula, which has a much higher modulus of elasticity and is less prone to collapse acutely over time, would be a good choice $[32,33]$.

\section{Conclusions}

Single-stage PTA surgery can simultaneously accomplish circumferential decompression, fibular allograft anterior implantation, and supplemental posterior instrumentation to salvage patients with symptomatic failed vertebroplasty. Good clinical outcomes and low complication rate can be achieved by this unique technique. Elderly patients usually cannot tolerate the prolonged and complex surgery. Therefore, single-stage PTA surgery could be specially considered as an alternative method to combined anterior and posterior surgeries for these fragile patients.

\section{Abbreviations}

PV: Percutaneous vertebroplasty; PMMA: Polymethyl-methacrylate; VCF: Vertebral compression fracture; PTA: Posterior transpedicular approach; VAS: Visual analog scale; FVC: Forced vital capacity; FEV1: Forced expiratory volume in $1 \mathrm{~s}$.

\section{Competing interests}

The authors declare that they have no competing interests.

\section{Authors' contributions}

YCC wrote the original manuscript. SCY coordinated the study design, carried out the literature search, and was responsible for drafting of the manuscript. HSC was responsible for the analysis and the interpretation of the data. YHK was responsible for the data acquisition. YKT provided expert clinic advice in the field and critically revised the manuscript. All authors read and approved the final manuscript.

\section{Acknowledgements}

The authors would like to express their warm thanks to all the staff of E-Da Hospital who contributed to the study.

Received: 4 September 2014 Accepted: 22 January 2015

Published online: 10 February 2015 


\section{References}

1. Galibert $P$, Deramond $H$, Rosat $P$, Le Gars D. Preliminary note on the treatment of vertebral angioma by percutaneous acrylic vertebroplasty. Neurochirurgie. 1987;33:166-8.

2. Deramond H, Depriester C, Galibert P, Le Gars D. Percutaneous vertebroplasty with polymethylmethacrylate. Technique, indications, and results. Radiol Clin North Am. 1998;36:533-46.

3. Murphy KJ, Deramond H. Percutaneous vertebroplasty in benign and malignant disease. Neuroimaging Clin N Am. 2000;10:535-45.

4. Ploeg WT, Veldhuizen AG, The B, Sietsma MS. Percutaneous vertebroplasty as a treatment for osteoporotic vertebral compression fractures: a systematic review. Eur Spine J. 2006;15:1749-58.

5. Yu SW, Lee PC, Ma CH, Chuang TY, Chen YJ. Vertebroplasty for the treatment of osteoporotic compression spinal fracture: comparison of remedial action at different stages of injury. J Trauma. 2004;56:629-32.

6. Chen WJ, Kao YH, Yang SC, Yu SW, Tu YK, Chung KC. Impact of cement leakage into disks on the development of adjacent vertebral compression fractures. J Spinal Disord Tech. 2010;23:35-9.

7. Grados F, Depriester C, Cayrolle G, Hardy N, Deramond H, Fardellone P. Long-term observations of vertebral osteoporotic fractures treated by percutaneous vertebroplasty. Rheumatology. 2000;39:1410-4.

8. Uppin AA, Hirsch JA, Centenera LV, Pfiefer BA, Pazianos AG, Choi IS. Occurrence of new vertebral body fracture after percutaneous vertebroplasty in patients with osteoporosis. Radiology. 2003;226:119-24.

9. Yang SC, Chen WJ, Yu SW, Tu YK, Kao YH, Chung KC. Revision strategies for complications and failure of vertebroplasties. Eur Spine J. 2008;17:982-8.

10. McDonnell MF, Glassman SD, Dimar JR, Puno RM, Johnson JR. Perioperative complications of anterior procedures of the spine. J Bone Joint Surg Am. 1996;78:839-46.

11. Faciszewski T, Winter RB, Lonstein JE, Denis F, Johnson L. The surgical and medical perioperative complications of anterior spinal fusion surgery in the thoracic and lumbar spine in adults. Spine. 1995;20:1592-9.

12. Akeyson EW, McCutcheon IE. Single stage posterior vertebrectomy and replacement combined with posterior instrumentation for spinal metastasis. J Neurosurg. 1996;85:211-20.

13. Sasani M, Ozer AF. Single-stage posterior corpectomy and expandable cage placement for treatment of thoracic or lumbar burst fractures. Spine. 2009:34:E33-40.

14. Lee SH, Sung JK, Park YM. Single-stage transpedicular decompression and posterior instrumentation in treatment of thoracic and thoracolumbar spinal tuberculosis: a retrospective case series. J Spinal Disord Tech. 2006;19:595-602.

15. Lu DC, Lau D, Lee JG, Chou D. The transpedicular approach compared with the anterior approach: an analysis of 80 thoracolumbar corpectomies. J Neurosurg Spine. 2010;12:583-91.

16. Brodsky AE, Hendricks RL, Khalil MA, Darden BV, Brotzman TT. Segmental ('floating') lumbar spine fusions. Spine. 1989;14:447-50.

17. Chiu YC, Yang SC, Chen HS, Kao YH, Tu YK, Chung KC. Clinical evaluation of repeat percutaneous vertebroplasty for symptomatic cemented vertebrae. J Spinal Disord Tech. 2012;25:E245-253.

18. Sharma R, Thng P, Gupta S, Saini N, Saini Y. Cement dislodgement after percutaneous vertebroplasty - a rare complication. Internet J Spine Surg. 2012;6:2.

19. Tsai TT, Chen WJ, Lai PL, Chen LH, Niu CC, Fu TS, et al. Polymethylmethacrylate cement dislodgment following percutaneous vertebroplasty: a case report. Spine. 2003;28:E457-460.

20. He SC, Teng GJ, Deng G, Fang W, Guo JH, Zhu GY, et al. Repeat vertebroplasty for unrelieved pain at previously treated vertebral levels with osteoporotic vertebral compression fractures. Spine. 2008;33:640-7.

21. Laredo JD, Hamze B. Complications of percutaneous vertebroplasty and their prevention. Semin Ultrasound CT MRI. 2005;26:65-80.

22. Yoo KY, Jeong SW, Yoon W, Lee J. Acute respiratory distress syndrome associated with pulmonary cement embolism following percutaneous vertebroplasty with polymethylmethacrylate. Spine. 2004;29:E294-297.

23. Lee BJ, Lee SR, Yoo TY. Paraplegia as a complication of percutaneous vertebroplasty with polymethylmethacrylate. Spine. 2002;27:E419-422.

24. Harrington KD. Major neurological complications following percutaneous vertebroplasty with polymethylmethacrylate. J Bone Joint Surg Am. 2001;83:1070-3.

25. Patel AA, Vaccaro AR, Martyak GG, Harrop JS, Albert TJ, Ludwig SC, et al. Neurologic deficit following percutaneous vertebral stabilization. Spine. 2007;32:1728-34
26. Vats HS, McKiernan FE. Infected vertebroplasty: case report and review of literature. Spine. 2006:31:E859-862.

27. Ikard RW. Methods and complications of anterior exposure of the thoracic and lumbar spine. Arch Surg. 2006;141:1025-34.

28. Börm W, Hübner F, Haffke T, Richter HP, Kast E, Rath SA. Approach-related complications of transthoracic spinal reconstruction procedures. Zentralbl Neurochir. 2004;65:1-6.

29. Visocchi M, Masferrer R, Sonntag VK, Dickman CA. Thoracoscopic approaches to the thoracic spine. Acta Neurochir. 1998;140:737-43.

30. Kurz LT, Garfin SR, Booth Jr RE. Harvesting autogenous iliac bone grafts. A review of complications and techniques. Spine. 1989;14:1324-31.

31. Schnee CL, Freese A, Weil RJ, Marcotte PJ. Analysis of harvest morbidity and radiographic outcome using autograft for anterior cervical fusion. Spine. 1997;22:2222-7.

32. Currey JD. The effect of porosity and mineral content on the Young's modulus of elasticity of compact bone. J Biomech. 1998;21:131-9.

33. Martin Jr GJ, Haid Jr RW, MacMillan M, Rodts Jr GE, Berkman R. Anterior cervical discectomy with freeze-dried fibula allograft. Overview of 317 cases and literature review. Spine. 1999;24:852-8.

\section{Submit your next manuscript to BioMed Central and take full advantage of:}

- Convenient online submission

- Thorough peer review

- No space constraints or color figure charges

- Immediate publication on acceptance

- Inclusion in PubMed, CAS, Scopus and Google Scholar

- Research which is freely available for redistribution 